\title{
A Comparative Study of the Physiological Parameters and Efficiency of the Various Types of Hemodialyzers
}

\author{
Albert E. Yousif ${ }^{1}$, Farah M. Abdul-Kareem ${ }^{2}$, Ali J. Mudhaffer ${ }^{3}$ \\ ${ }^{1}$ Professor, Medical Engineering Department, College of Engineering, alnahrain University, Baghdad, Iraq \\ ${ }^{2}$ Graduate student, Medical Engineering Department, College of Engineering, alnahrain University, Baghdad, Iraq \\ ${ }^{3}$ Consultant Internist-Nephrologists, Kidney Disease and Transplant Center, the Medical City Hospital, Baghdad, Iraq \\ Email address: \\ farah.mohanad88@gmail.com (F. M. Abdul-Kareem)
}

\section{To cite this article:}

Albert E. Yousif, Farah M. Abdul-Kareem, Ali J. Mudhaffer. A Comparative Study of the Physiological Parameters and Efficiency of the Various Types of Hemodialyzers. American Journal of Bioscience and Bioengineering. Vol. 3, No. 2, 2015, pp. 8-16.

doi: $10.11648 /$ j.bio. 20150302.11

\begin{abstract}
The work presented in this paper is intended to compare the physiological parameters and "efficiency" (the capacity to remove Urea, while "Flux" refers to the capacity to remove water, and indirectly, the capacity to remove molecules of middle molecular weight for the three basic types of dialyzer (twin coil, parallel plate, and hollow fiber). A comparative study of the operational parameters ,that is, ( clearance, resistance, permeability (which means efficiency with removing molecules of small molecular weight ), membrane surface area, time, and clearance ratio (extraction ratio). The most desirable property of a hemodialysis membrane is high mass transfer of toxic solutes to reduce the dialysis time, blood compatibility and limited protein adsorption capacity. This was achieved in the hollow fiber dialyzer which has relatively high mass transfer as compared to that of the parallel plate and also for the twin coil dialyzer all having about the same membrane surface area. Dialysis treatment was given to 65 patients with kidney failure; 25 patients for the study of clearance and permeability, and 40 patients for the study of dialysis adequacy. The treatment time was found to be approximately about half the time for the hollow fiber dialyzer as compared to the Kiil and Kolff dialyzers of about the same membrane surface area. This reduction in treatment time is extremely advantageous for the patient endurance and comfort.
\end{abstract}

Keywords: Dialyzer Efficiency, Kolff Dialyzer, Kiil Dialyzer, Hollow Fiber Dialyzer, Urea Clearance

\section{Introduction}

An understanding of osmosis, diffusion, and semipermeable membranes began to emerge in the mid-1800s. There are two ways solutes can be moved through a membrane: diffusion and convection. Diffusion means small solute transport across the dialysis membrane in a direction dictated by the concentration gradient established across the membrane of the hemodialysis. Urea moves from blood to the dialysate, while calcium and acetic acid move from the dialysate to blood. The concentration gradient across the membrane drives the movement of solutes. Diffusion is affected by blood, dialysate flow rates, temperature, and surface area of the dialyzer and thickness of the membrane. Assuming that all other factors are constant, the diffusion process is basically dependent on the concentration gradient between blood and dialysate. This is strongly affected by the blood and dialysate flow rates and by the distribution of the countercurrent flows in their relative compartments $[1,2]$.
Ultrafiltration is the passage of fluid under pressure difference across a semi-permeable membrane where solutes are carried along with the fluid by solvent drag (convection), where the convection pulls solution and solutes across a membrane [3]. The positive pressure of blood is higher than the negative pressure of the dialysate and by adjusting the negative pressure, the amount of filtrated water may be controlled [1]. Thomas Graham, a professor of chemistry in Glasgow, first coined the phrase dialysis in 1854 when he described the movement of various types of solutes through a membrane forced by osmotic pressures [3]. Although various diseases of the kidney may initially attack a specific area of the organ (e.g., the glomeruli, the tubules) progression of the diseases often leads ultimately to severe general impairment of kidney function.

When substantial or total inability of the kidneys to remove water, metabolic wastes, and excess electrolytes from the body exists, death is normally only a matter of days away [4]. The techniques used to perform the kidneys' excretory functions 
are hemodialysis and peritoneal dialysis and others. The general term "dialysis" means to separate substances using a membrane. The artificial kidney is an apparatus that utilizes a process termed hemodialysis to remove excess substances from the blood [5]. There are various types of artificial kidney but the basic types that studied in the presented work are: the hollow fiber, parallel plate, and twin coil dialyzers. Their operational factors and efficiencies are compared based on theoretical considerations and actual dialysis treatment results.

\section{Experimental Work}

\subsection{Dialysis Treatment: This Requires a Hemodialysis Machine, Dialyzer, Dialysate Fluid, and Blood Sample}

The dialysis treatment was given to 65 patients with kidney failure; 25 patients for the study of clearance and permeability, and 40 patients for the study of dialysis adequacy $(\mathrm{Kt} / \mathrm{V})$. They were connected to the artificial kidney device for a period of 2-4 hours, three times a week at the Medical City Hospital in Baghdad. The dialyzer was of the hollow fiber type. The hemodialysis machine allows dialysis treatment without any additional equipment .The machine operates and monitors the dialysate circuit and the extracorporeal blood circuit. The required treatment parameters can be entered via various menus provided for programming and displaying on a high resolution LC display . The current treatment data are shown on the display. The dialyzer (membrane): is a part in the artificial kidney system in which the treatment actually takes place and the blood is freed from the waste products. It is the meeting point of two circuits, one in which the blood circulates and the other in which dialysis fluid flows. These two compartments are separated by a semipermeable membrane and form a closed self-contained system. There are various types of dialyzers with different areas. These are:

(i) Fresenius medical care (F): F4 (A=0.8 m2); F5 (A=1 m2); F6 $\quad(\mathrm{A}=1.3 \mathrm{~m} 2) ; \quad \mathrm{F} 7 \quad\left(\mathrm{~A}=1.6 \mathrm{~m}^{2}\right) ; \quad \mathrm{F} 8 \quad(\mathrm{~A}=1.8 \mathrm{~m} 2) ; \quad \mathrm{F} 10$ $(\mathrm{A}=2.2 \mathrm{~m} 2)$.

(ii) Gambro polyflux (L): 17L $\left(\mathrm{A}=1.7 \mathrm{~m}^{2}\right)$,

$21 \mathrm{~L}\left(\mathrm{~A}=2.1 \mathrm{~m}^{2}\right)$.

The dialysis machine mixes the bicarbonate and acid concentrates and water which contain concentrates and water at ratio 1:35 to form the dialysate which is used to clean the patient blood from waste product. $2 \mathrm{~cm} 3$ blood samples for urea measurement were taken after $15 \mathrm{~min}$ from the 25 patient connected to the device, some of them gave four samples, two at specific blood flow rate before and after dialyzer, and two after nearly 1 hour at another blood flow rate before and after dialyzer, patients gave two samples at specific blood flow rate before and after dialyzer. As follow:

1. Dialyzer with area $1 \mathrm{~m}^{2}: 6$ patients were utilized, two patients with 150 and $200 \mathrm{ml} / \mathrm{min}$; two patients with 250 and $300 \mathrm{ml} / \mathrm{min}$; 1 patient with $250 \mathrm{ml} / \mathrm{min}, 1$ patient with 200 and $300 \mathrm{ml} / \mathrm{min}$ flow rates.

2. Dialyzer with area $0.8 \mathrm{~m}^{2}$, one patient was examined at $200,300 \mathrm{ml} / \mathrm{min}$ flow rates.

3. Dialyzer with area $1.3 \mathrm{~m}^{2}$, three patients were examined at
200 and $300 \mathrm{ml} / \mathrm{min}$ flow rates.

4. Dialyzer with area $1.6 \mathrm{~m}^{2}, 2$ patients were tested at 200 and $300 \mathrm{ml} / \mathrm{min}$ and one at $250 \mathrm{ml} / \mathrm{min}$ flow rates respectively.

5. Dialyzer with area $1.8 \mathrm{~m}^{2}$, two patients were tested with $200,300 \mathrm{ml} / \mathrm{min}$ flow rates respectively.

6. Dialyzer with area $2.2 \mathrm{~m}^{2}$, 1patient was tested at $200 \mathrm{ml} / \mathrm{min}, 1$ at 200 and $350 \mathrm{ml} / \mathrm{min}$, and 1 at 200 and 300 $\mathrm{ml} / \mathrm{min}$ flow rates.

7. Dialyzer with area $2.1 \mathrm{~m}^{2}$, four patients were examined, one at 200, and two at 300 and the fourth at $350 \mathrm{ml} / \mathrm{min}$ flow rates.

8. Dialyzer with area $1.7 \mathrm{~m}^{2}$, three patients were examined, one at $200 \mathrm{ml} / \mathrm{min}$, another at 250 and $300 \mathrm{ml} / \mathrm{min}$, and the third at $300 \mathrm{ml} / \mathrm{min}$ flow rates. The blood samples were used with heparin to prevent blood clotting. They were taken before dialyzer from the arterial line, and after leaving the dialyzer, taken from the venous line by tubes used to collect the blood sample for laboratory tests.

\subsection{Dialysis Factors}

\subsubsection{Clearance}

Blood samples have been drawn from the patients at the beginning of dialysis session (Pre-dialysis), and at the end of dialysis (Postdialysis) immediately, and applying them in equation (1) [6] for clearance with blood flow rates 150, 200, $250,300,350 \mathrm{ml} / \mathrm{min}$ for different areas $(0.8,1,1.3,1.6,1.8$, $\left.2.2,1.7,2.1 \mathrm{~m}^{2}\right)$, the clearance values for hollow fiber dialyzer were obtained. For Kiil and Kolff dialyzer, the clearance values were taken from literature in order to compare them with those of the hollow fiber dialyzer because they are not available at present in the local hospitals.

$$
K=\frac{Q_{b i}\left(C_{b i}-C_{b o}\right)}{C_{b i}}
$$

Where $\mathrm{K}$ is the clearance in $\mathrm{ml} / \mathrm{min}, C_{b i}, C_{b o}$ are the blood concentrations inlet and outlet the dialyzer taken from the patient blood and $Q_{b}$ is the blood flow rate.

\subsubsection{Dialysis Time}

Depending on the data in the literature $\left(\mathrm{K}_{\mathrm{o}} \mathrm{A}\right)$ for coil, parallel plate and hollow fiber dialyzer, with selected set for parameters $\left(C_{b i}, C_{b o}, Q_{b}, \mathrm{~A}, V_{b}\right)$ equal (150mg \%, 50mg\%, $200 \mathrm{ml} / \mathrm{min}, 1 \mathrm{~m}^{2}, 50000 \mathrm{ml}$ ) respectively [4], This data was fixed for (coil, parallel plate and hollow fiber dialyzer) for the purpose of comparison of the operational parameters and the efficiency of the three types of dialyzers. The dialysis session time was obtained by applying equation (2) below:

$$
t=\ln \frac{C_{b i}}{C_{b i}{ }^{o}} \cdot \frac{V_{b}}{Q_{b}(\beta-1)}
$$

Where $\beta=\exp \left(-\frac{K_{o} A}{Q_{b}}\right)$ 


\subsubsection{Extraction Ratio (E)}

Extraction ratio or clearance ratio is the fraction of solute removal. By applying equations (3) and (4) and using the data in the literature for different area, blood and dialysate flow rates $\left(Q_{b}, Q_{d}\right)$, and mass transfer coefficient, the values of $\mathrm{E}$ obtained with $\mathrm{Z}=0,1$, 2.for different $N T$ values, all being dimensionless $[4,7]$.

For countercurrent flow:

$$
E=\frac{1-\exp \left[N_{T}(1-Z)\right]}{Z-\exp \left[N_{T}(1-Z)\right]}
$$

Or, if $\mathrm{Z}=1$,

$$
E=\frac{N_{T}}{1+N_{T}}
$$

Where $\mathrm{Z}=Q_{b} / Q_{d} ; N_{T}=\mathrm{K}_{\mathrm{o}} \mathrm{A} / Q_{b}$

The results obtained by taking $\mathrm{K}_{0} \mathrm{~A}$ with different values from manufacturer data sheet divided by the blood flow rate $100,200,300,400 \mathrm{ml} / \mathrm{min}$, for the hollow fiber dialyzer, however ,for Kiil and Kolff dialyzers these values were taken from the literature. The results obtained were compared with (E) against (Z) for countercurrent flow in the literature.

\subsubsection{Permeability (P)}

Taking the result of concentrations $\left(C_{b i}, C_{b o}\right)$ of blood sample before and after dialyzer, and applying them in equation (5) and (6) to obtain permeability value (P) $\left(\frac{\mathrm{ml}}{\mathrm{min}}\right)$ and equation (7) to obtain $\left(\mathrm{Pm}^{2}\right)$ value [8].

$$
\begin{gathered}
D=Q_{b} \frac{A-R}{A-U}=Q_{b} . E \\
P=-\ln (1-E) Q_{b} \\
P m^{2}=-\ln (1-E) \frac{Q_{b}}{A}
\end{gathered}
$$

\subsubsection{Overall Resistance $\left(\boldsymbol{R}_{o}\right)$}

The overall mass transfer coefficient $\left(\mathrm{K}_{0}\right)$ is the inverse of an overall resistance which in turn is the sum of the blood side, membrane, and dialysate side mass transfer resistance, as shown in equation (8). the values of the overall resistance was obtained for the hollow fiber dialyzer with areas $\left(0.8,1,1.3,1.4,1.6,1.7,1.8,2.1,2.2 \mathrm{~m}^{2}\right)$ and with values of $\left(\mathrm{K}_{0} \mathrm{~A}\right)$ from the manufacturer data sheet for each area. And these compared with the overall resistance values for the Kiil and Kolff dialyzer from the literature $[4,6]$.

$$
\frac{1}{K_{o}}=R_{o}=R_{B}+R_{M}+R_{D}=\frac{\Delta x_{B}}{D_{B}^{\prime \prime}}=\frac{\Delta x_{M}}{k D_{M}^{\prime \prime}}=\frac{\Delta x_{D}}{D_{D}^{\prime \prime}}
$$

\subsubsection{Dialysis Adequacy}

40 patients were taken to obtain the values of Kt/V ( $s p \mathrm{Kt} / \mathrm{V}$
[9, 10], URR [11], e Kt/V [12]) which determine the dialysis adequacy .Blood samples for Kt/V differ from blood samples for clearance because they need special technique .These samples were taken at blood flow rate 200 and $300 \mathrm{ml} / \mathrm{min}$ to show the effect of $Q_{b}$ on the $\mathrm{Kt} / \mathrm{V}$ values. The values of ( $\mathrm{sp}$ $\mathrm{Kt} / \mathrm{V}$, URR, e $\mathrm{Kt} / \mathrm{V}$ ) were drawn against four groups of dialyzer types (Group 1: dialyzer with area $1 \mathrm{~m}^{2}$, Group 2: dialyzer with area $1.3 \mathrm{~m}^{2}$, Group 3: dialyzer with area $1.7 \mathrm{~m}^{2}$, Group 4: dialyzer with area $2.1 \mathrm{~m}^{2}$ ) to show the effect of surface area on the Kt/V values, using equations (9), (10), and (11):

$$
\begin{gathered}
s p K t / V_{\text {urea }}=-\ln (R-0.008 t)+(4-3.5 R) U F / W \\
U R R=\frac{100\left(C_{o}-C_{t}\right)}{C_{o}} \\
e K t / V_{\text {urea }}=s p K t / V_{\text {urea }}-0.6(K / V)+0.03
\end{gathered}
$$

\section{Results}

\subsection{Clearances}

The clearance values obtained for the hollow fiber dialyzer with area $1 \mathrm{~m}^{2}$, at $Q_{b}=200 \mathrm{ml} / \mathrm{min}$, was $119.22 \mathrm{ml} / \mathrm{min}$. At $Q_{b}=300 \mathrm{ml} / \mathrm{min}$., the clearance value was $162.5 \mathrm{ml} / \mathrm{min}$. as shown in figure (1- a) compared with ( $1 \mathrm{~b})$ and (1c) for the Kiil and Kolff dialyzer. Clearance values of hollow fiber dialyzer with membrane from polysulfone material for different areas are shown in figure (2). Clearance values of hollow fiber dialyzer with membrane from polyflux material for different areas are shown in figure (3). Comparison between polyflux $\left(\mathrm{A}=2.1 \mathrm{~m}^{2}\right)$ and polysulfone membrane $\left(\mathrm{A}=2.2 \mathrm{~m}^{2}\right)$ shown in figure (4). The clearance value increases with increasing the dialyzer surface area with different blood flow rates as shown in figure (5). As both values of $\mathrm{K}_{0} \mathrm{~A}$ and $Q_{b}$ increase; the clearance values increase, as shown in figure (6) below, for $Q_{b}=200 \mathrm{ml} / \mathrm{min}$ and $300 \mathrm{ml} / \mathrm{min}$.

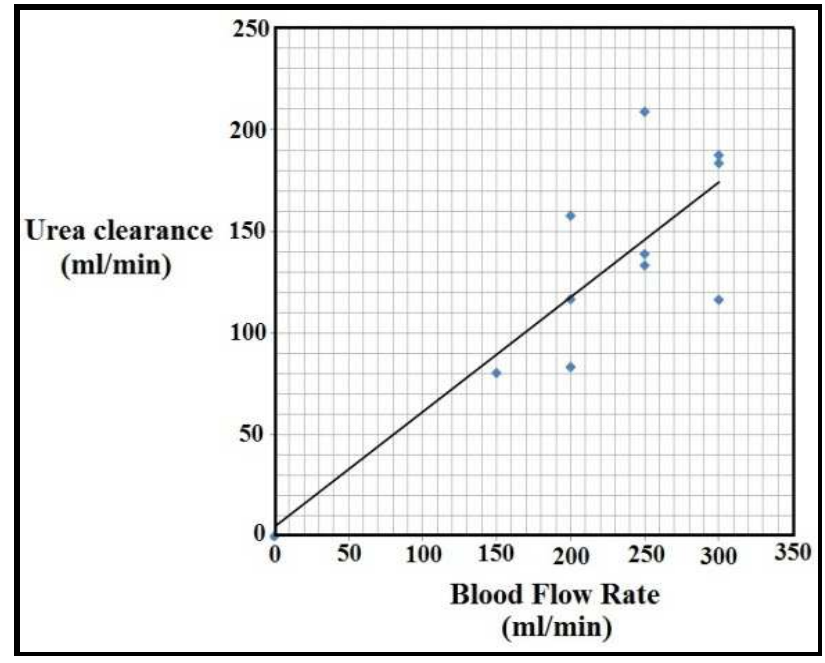

(a) 


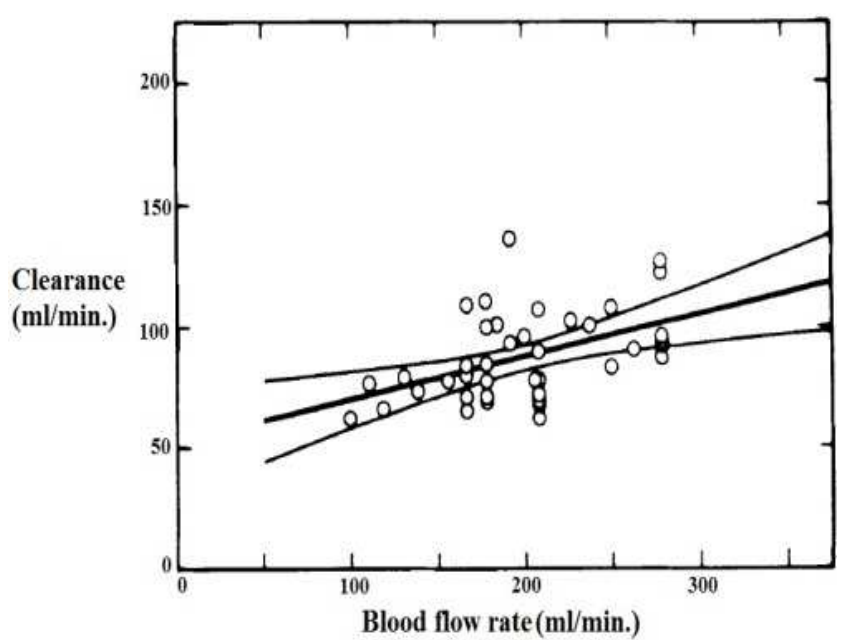

(b)

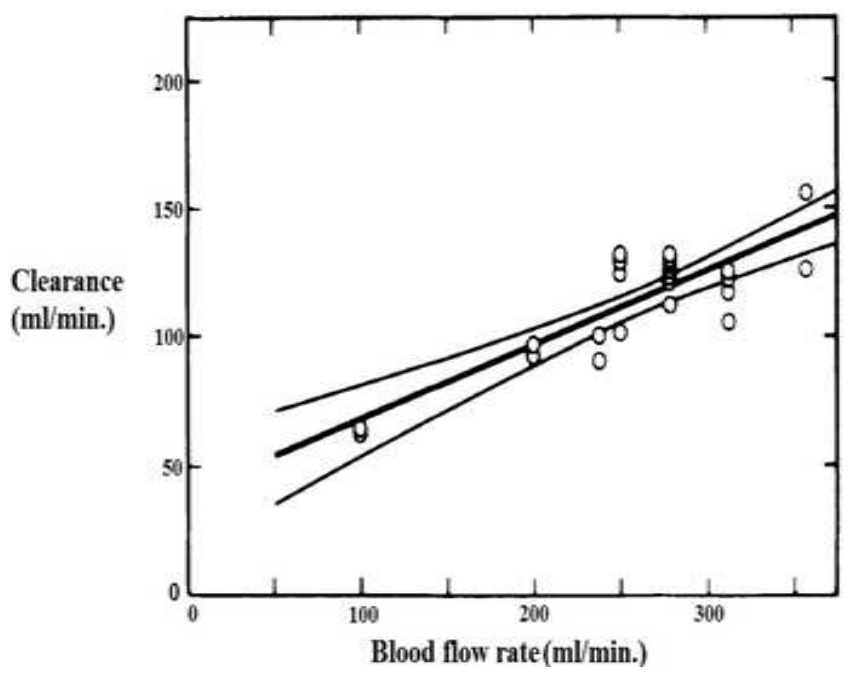

(c)

Fig. (1). Basic types of artificial kidneys. (a) hollow fiber dialyzer (b) Kiil dialyzer (c) Kolff dialyzer, both (b) and (c) from [13].

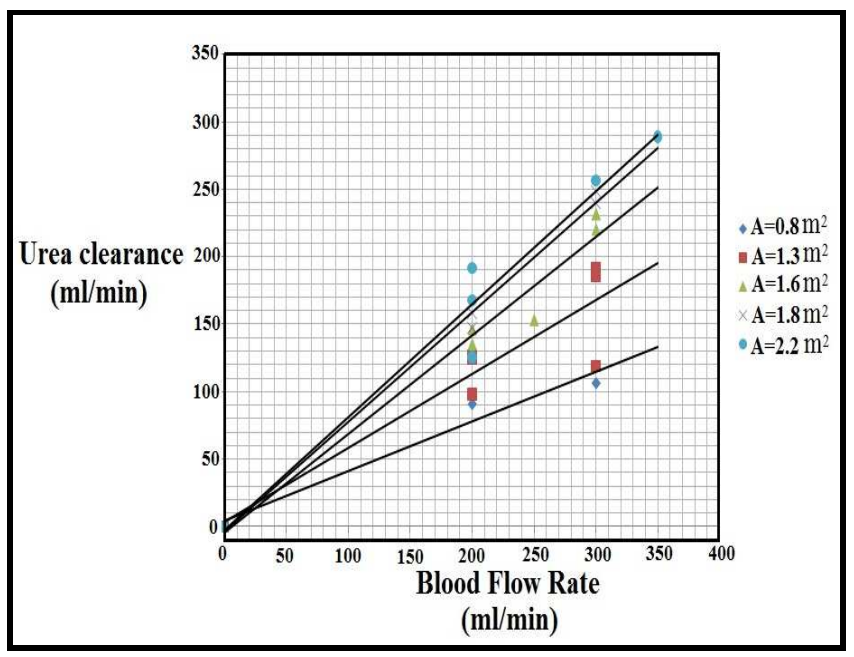

Fig. (2). Shows the clearance against blood flow rate for the capillary dialyzer with polysulfone membrane.

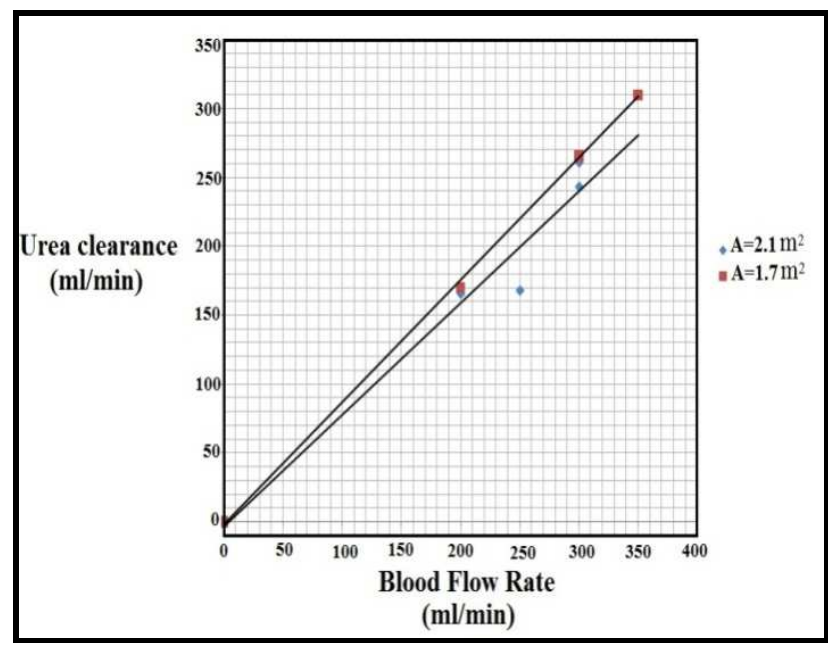

Fig. (3). Shows the clearance against blood flow rate for the capillary dialyzer polyflux membrane.

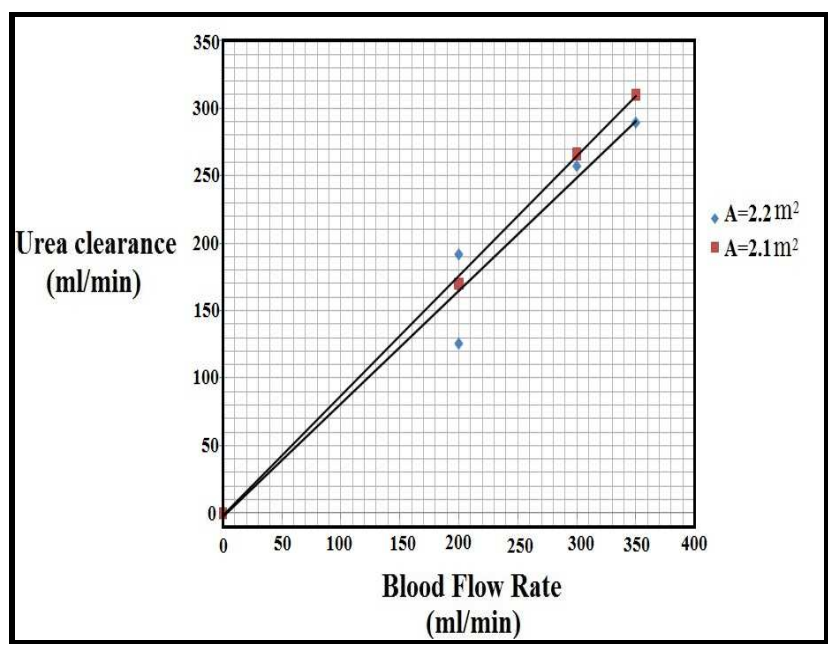

Fig. (4). Shows the clearance against blood flow rate for the capillary dialyzer show the differences between polyflux and polysulfone membrane approximately with the same surface area.

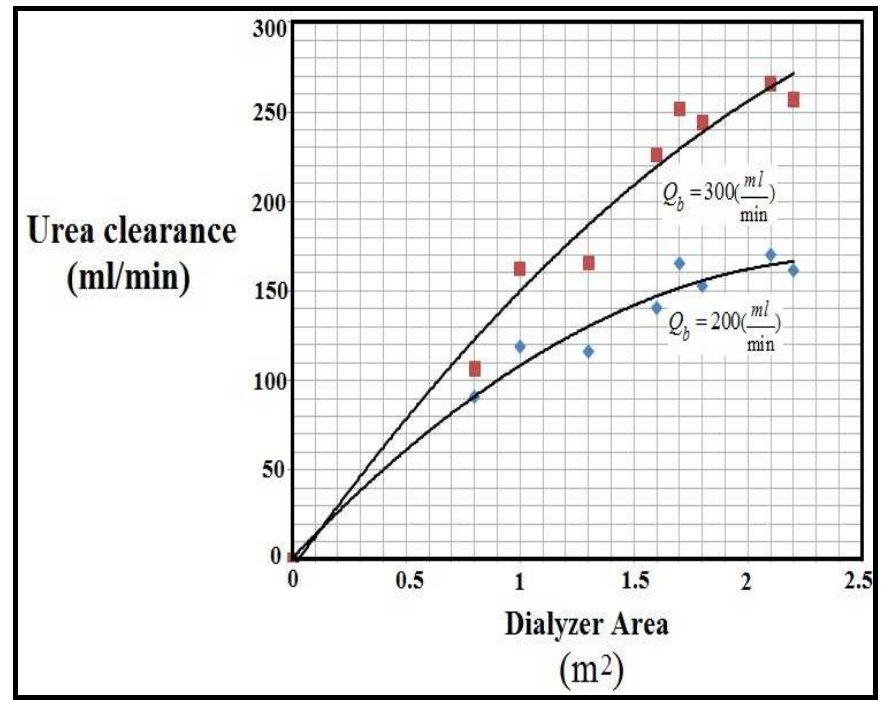

Fig. (5). Shows the effect of increasing dialyzer surface area on the clearance value with different blood flow rate for the capillary dialyzer. 


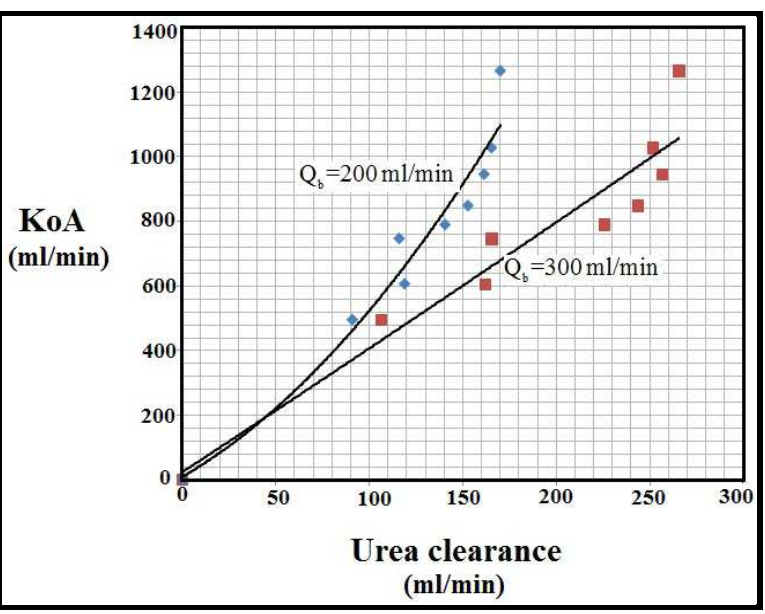

Fig. (6). Shows the effect of increasing $K_{o} A$ with the clearance at $Q_{b}=200 \mathrm{ml} / \mathrm{min}$, and $300 \mathrm{ml} / \mathrm{min}$.

\subsection{Session Times $(t)$}

The values of time for the dialyses session was predicted for the Kiil, Kolff and Hollow fiber dialyzer as in figure (7), the differences in time between the polysulfone and polyflux materials used in the hollow fiber dialyzer are not very large and it is convergent as in figure (8).

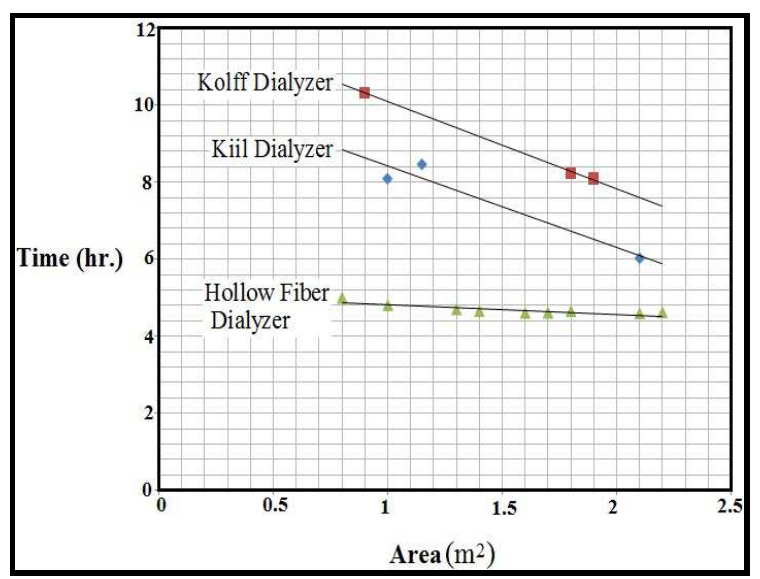

Fig. (7). Shows the variation in times for the basic three types of dialyzer (Kiil, Kolff and Hollow fiber dialyzer).

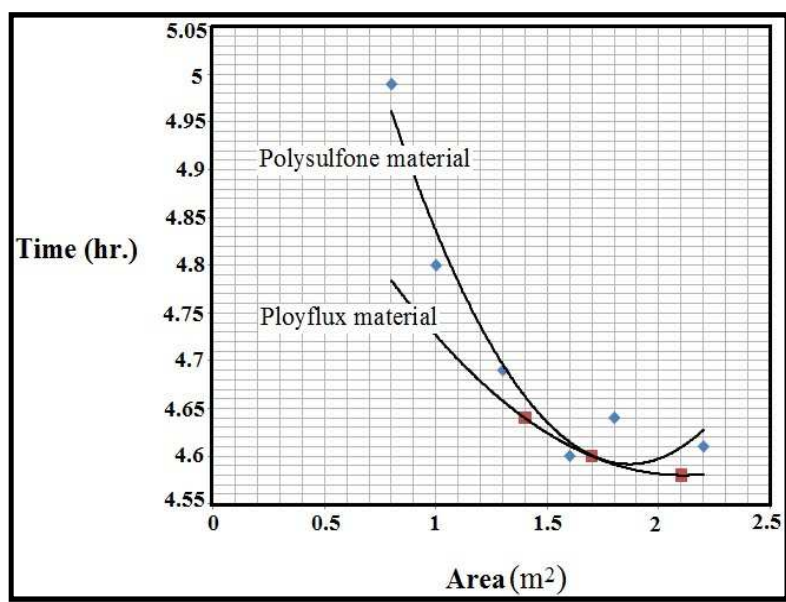

Fig. (8). Show the differences in time between the polysulfone and polyflux materials used in the hollow fiber dialyzer.

\subsection{Extraction Ratio (E)}

The values of $\mathrm{E}$ were obtained for the Hollow fiber dialyzer as in figure (9), Kiil dialyzer as in figure (10), and Kolff dialyzer as in figure (11).

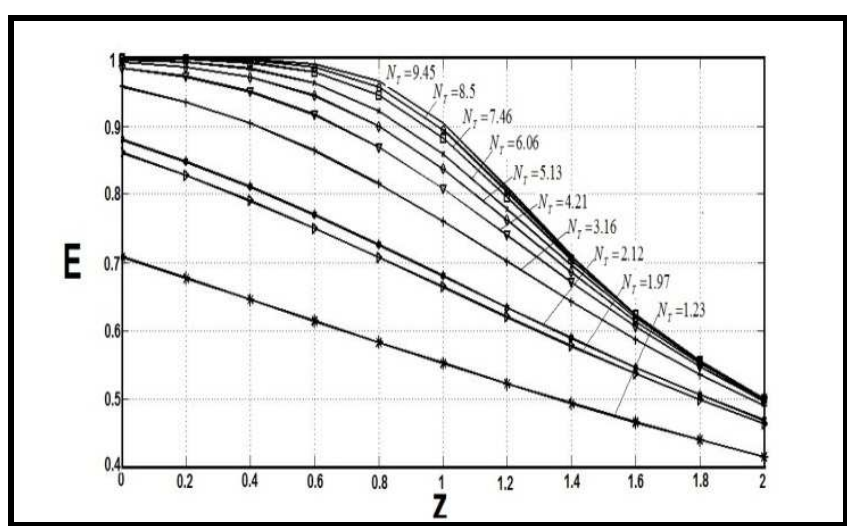

Fig. (9). Shows extraction ratio (E) against $Z$ flow ratio for different $N_{T}$ values for Hollow fiber dialyzer.

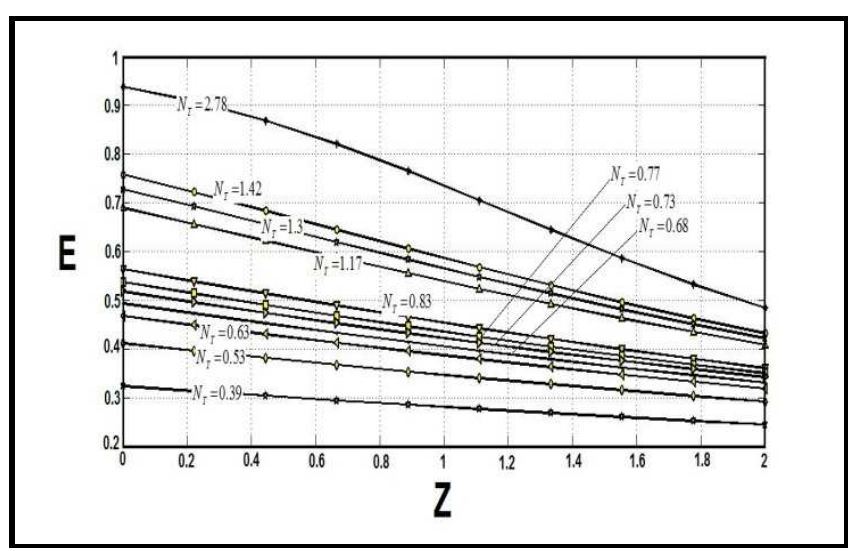

Fig. (10). Extraction ratio (E) against $Z$ flow ratio with different $N_{T}$ values for Kiil dialyzer

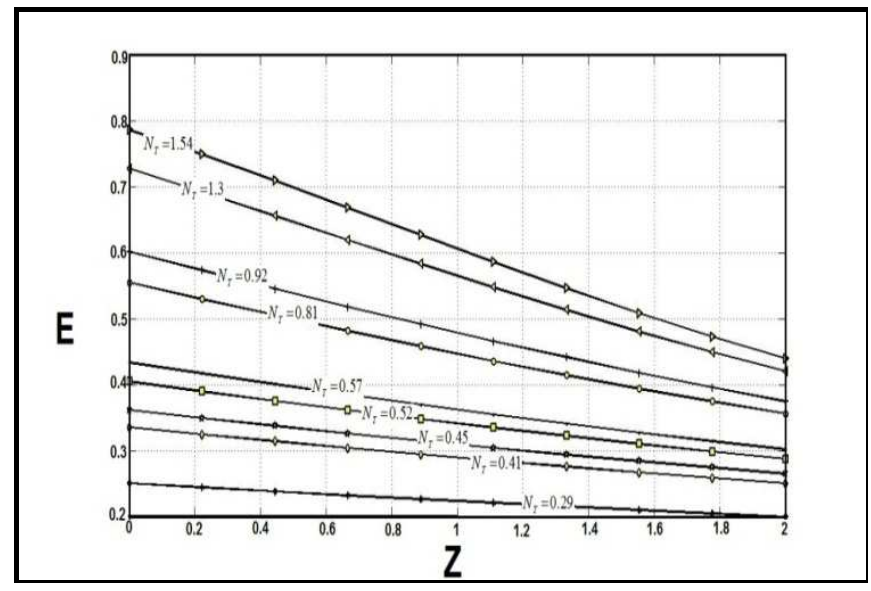

Fig. (11). Extraction ratio (E) against Z flow ratio with different $N_{T}$ values for Kolff dialyzer.

Curves (9), (10) and (11) for countercurrent flow can be compared with figure (12), given in [4] for general agreements. 


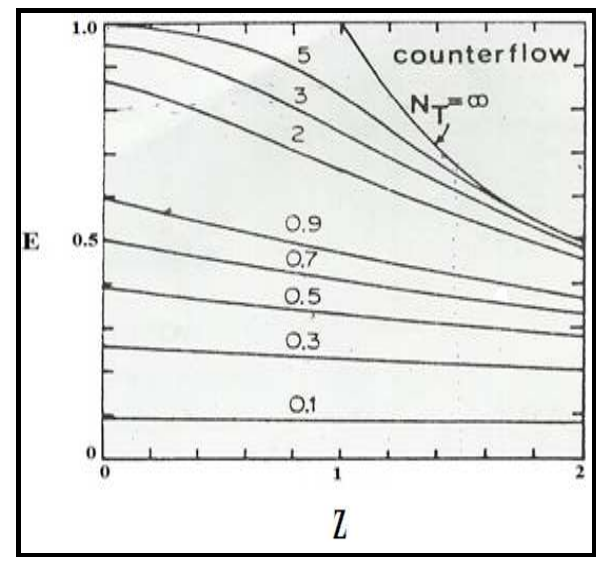

Fig. (12). Shows the variation of the extraction ratio (E) against $Z$ flow ratio $\left(Q_{b} / Q_{d}\right)$ representing the performance profiles for a countercurrent flow dialyzer [4].

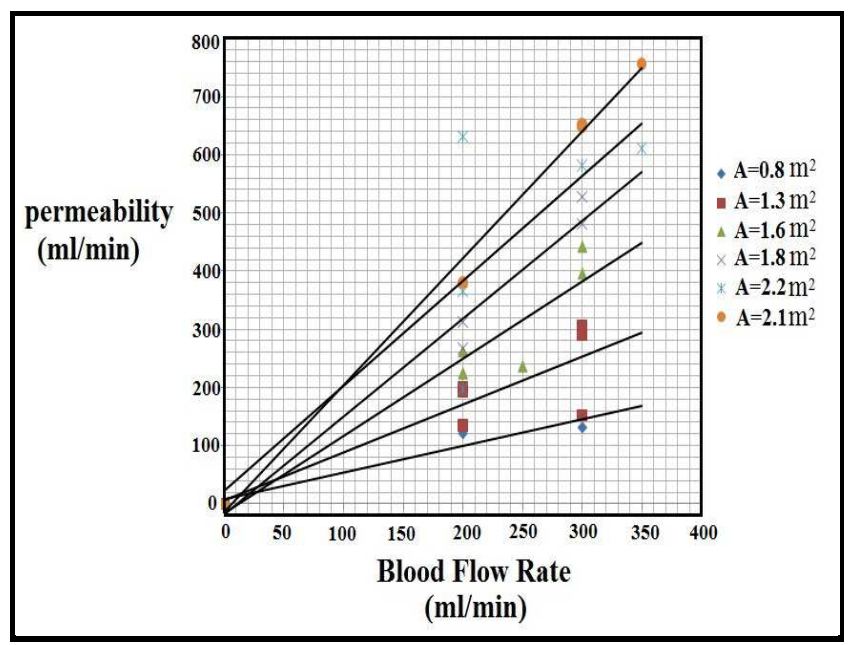

Fig. (13). Shows the permeability variation with blood flow rate at different areas.

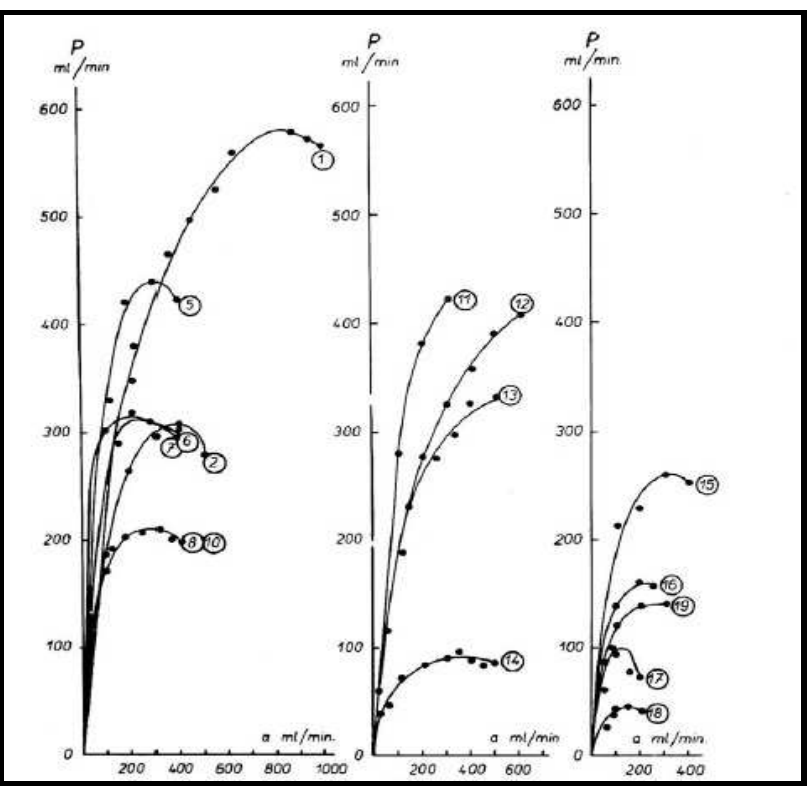

Fig. (14). Relations of permeability $(P)$ to blood flow rate, the numbers in circles denote the same as in table (A-1) in the appendix [8].

\subsection{The Permeability (P)}

The values of permeability for Hollow fiber dialyzer was obtained as figure (13), and compared these results with the results of Kiil and Kolff dialyzer as shown in table( A-1) in the appendix and in figure (14).

\subsection{The overall Resistance $\left(R_{\circ}\right)$}

The values of the overall resistance $\left(\mathrm{R}_{\mathrm{o}}\right)$ are obtained as shown in figure (15) depending on the overall mass transfer-area coefficient $\left(\mathrm{K}_{0} \mathrm{~A}\right)$ for the hollow fiber dialyzer with different areas and for Kiil and Kolff dialyzer is as in the literature.

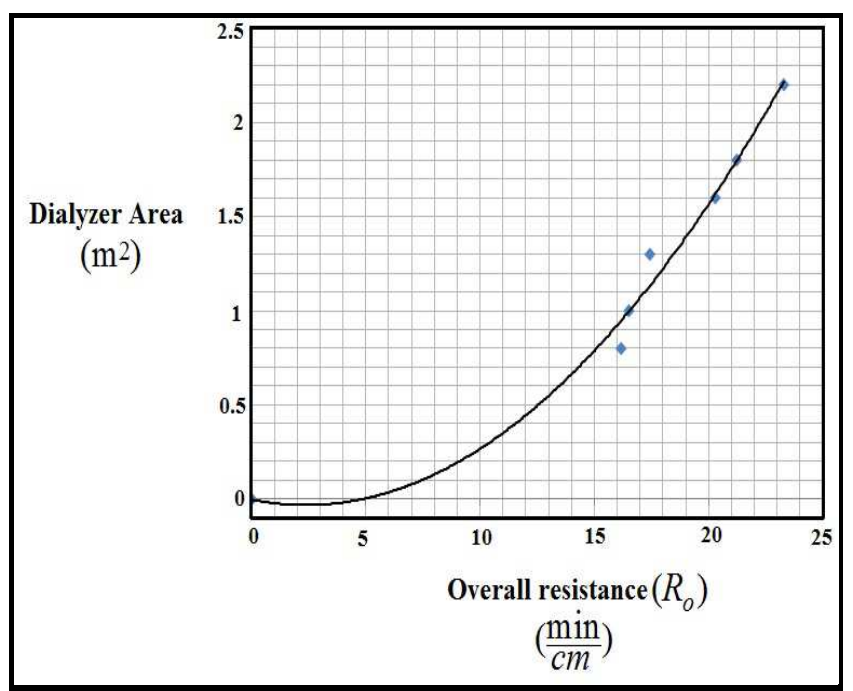

Fig. (15). Shows the effect of increasing dialyzer surface area $\left(\mathrm{m}^{2}\right)$ on overall resistance $R_{o}(\mathrm{~min} / \mathrm{cm})$.

\subsection{Dialysis Adequacy}

The results obtained are presented in figures (16), (17), (18):

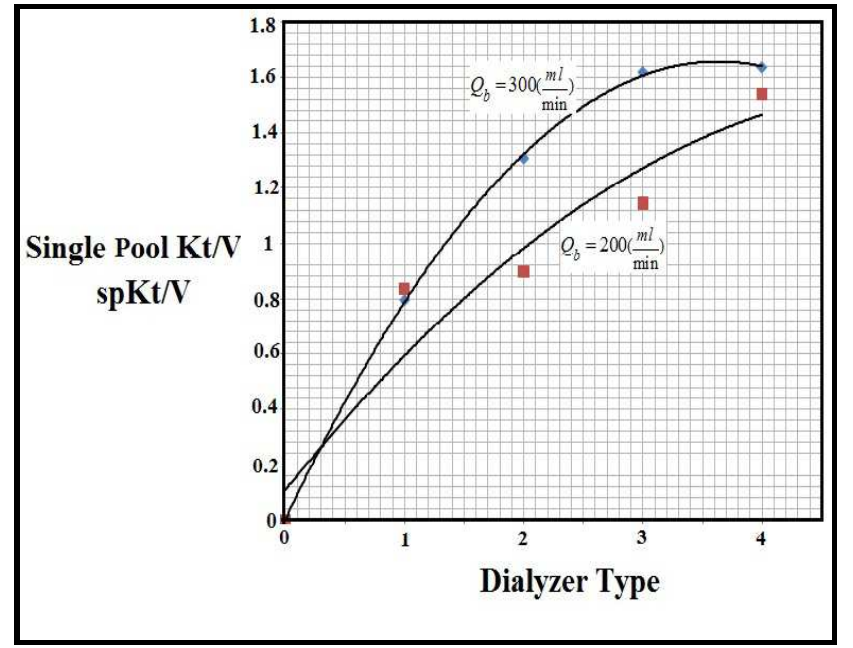

Fig. (16). Shows the effect of dialyzer type (each type have a different area) and blood flow rate on the single pool Kt/V (sp Kt/V). 


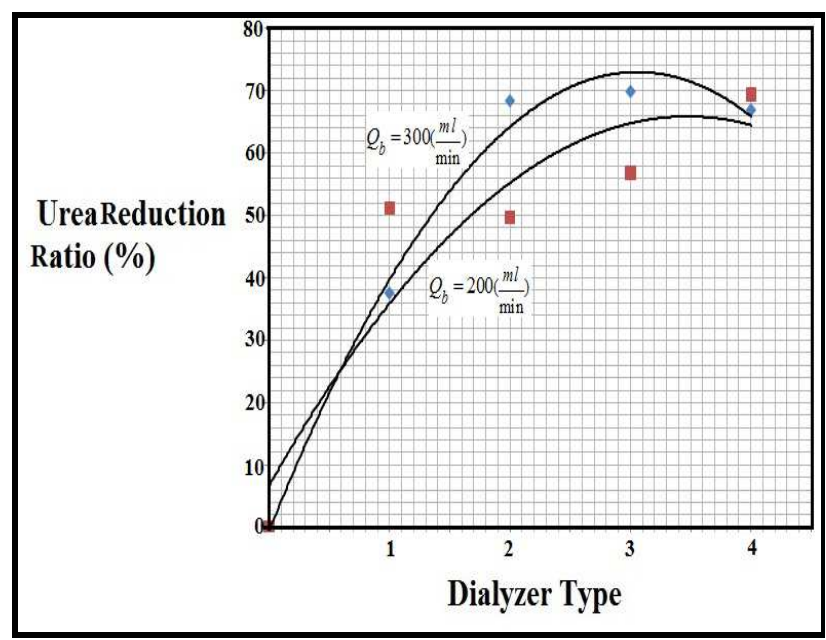

Fig. (17). Shows the effect of dialyzer type (each type have a different area) and blood flow rate on the Urea reduction ratio (URR).

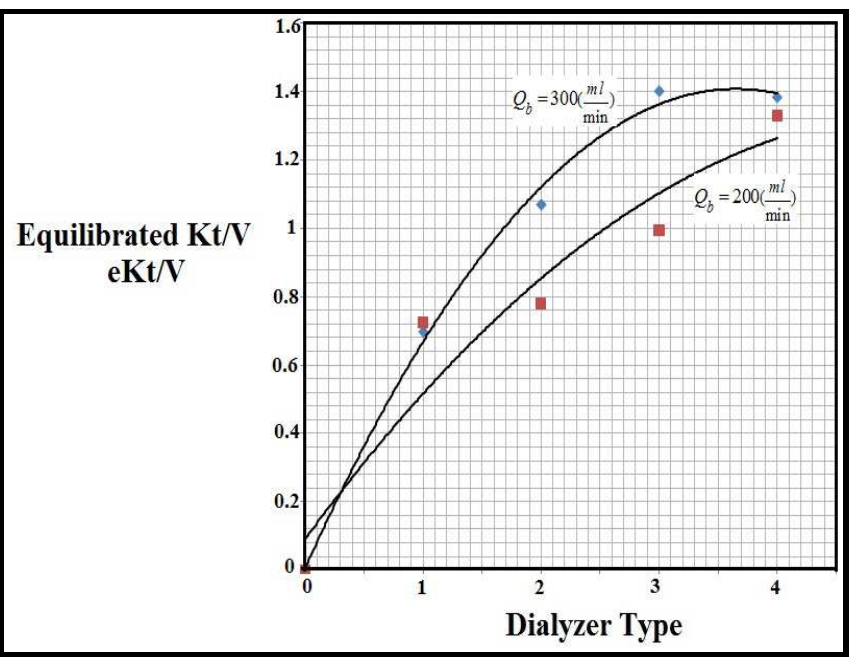

Fig. (18). Shows the effect of dialyzer type (each type have a different area) and blood flow rate on the equilibrated $\mathrm{Kt} / \mathrm{V}(\mathrm{eKt} / \mathrm{V})$.

\section{Discussion}

One of the most important parameters for comparing the efficiency (capacity to remove urea) between the different types of dialyzer is the clearance. Clearance values for hollow fiber dialyzer is larger than those for Kiil and Coil dialyzers, clearance values are higher for coil than for Kiil as in figure $(1 \mathrm{a}, \mathrm{b}, \mathrm{c})$ but for modified Kiil it is larger than that for coil as reported in references [13, 14]. Session time decreases with increasing area. The dialysis session time for the Kiil dialyzer range 6-8 hour with different areas, for Kolff dialyzer it is about 8-10 hour in one session, however, the Kiil dialyzer showed almost 1 hour lesser time than Kolff and this is very bothersome and tedious for the patient while the hollow fiber dialyzer showed almost the lowest constant time ( 4 hour) than both Kiil and Kolff dialyzers. This is considered a great improvement on the design of the other two dialyzers as seen in figures (7) .Figure (8) showed almost low variations between the different materials used especially in the working range of the area $\left(1.4-2.1 \mathrm{~m}^{2}\right)$.Thus the advent of hollow fiber dialyzers greatly increase the efficiency of small solute removal and lead to shorten treatment time. The blood samples taken from the patient at blood flow rates $200,300 \mathrm{ml} / \mathrm{min}$ and occasionally at 250 , $350 \mathrm{ml} / \mathrm{min}$ according to the patient health state and below this not advised because the reduction in blood flow rate can predispose to clotting in the extracorporeal circuit .Also if the blood flow is slowed, then very little amount of urea will be removed. The blood leaving the dialyzer has a lower concentration of waste products than the blood entering the dialyzer. The clearance values of the hollow fiber dialyzer for different areas are varied and they increase with increasing area for the same dialyzer as shown in figures (2), (3) and (5). Membranes of Polyamide and polysulfone dialyzer material used in this study differ in their material, ultrafiltration coefficient, clearances of small and large molecules, area of membrane, biocompatibility and suitability for re-use but the differences in clearance and time between these two materials is very low as shown in figure (4). Clearance values for polyamide with area $2.1 \mathrm{~m}^{2}$ are higher than those for polysulfone with area $2.2 \mathrm{~m}^{2}$ due to different materials as given in the manufacturer data sheets. The modern trend is towards the use of dialyzers containing membranes manufactured from synthetic polymers. The use of unmodified cellulose such as cuprophan is declining, and its future production is uncertain. Another characteristic of dialyzer is the mass transfer-area coefficient $\mathrm{K}_{0} \mathrm{~A}(\mathrm{ml} / \mathrm{min})$ which is the maximum theoretical clearance of the dialyzer in $\mathrm{ml} / \mathrm{min}$, It differs from one dialyzer to another according to the dialyzer surface area where it increases with increasing the area and dialysate flow rate (increases from 500 to 800 $\mathrm{ml} / \mathrm{min}$ ) with no change at various blood flow rates as given in [15].The value of $\mathrm{K}_{0} \mathrm{~A}$ determines the efficiency of the dialyzer whether it is low, moderate or high. In this study, the $\mathrm{K}_{0} \mathrm{~A}$ values for Kolff and Kiil dialyzer have been taken from reference [4] while for capillary dialyzer was taken from the manufacturer data sheet. It is found that when the $\mathrm{K}_{0} \mathrm{~A}$ values increase the clearance values increase with increasing area for blood flow rates 200 or $300 \mathrm{ml} / \mathrm{min}$, with fixed dialysate flow rate $(500 \mathrm{ml} / \mathrm{min})$ as shown in figure (6). The performance index or extraction ratio (E) for Kolff, Kiil and capillary dialyzer were also obtained for the countercurrent flow. It is clear from this study that the E values increase as the ratio $Q_{b} / Q_{d}$ or $(\mathrm{Z})$ becomes smaller, and increases as the membrane area and mass transfer coefficient become larger. For increasing values of $N_{T}$, E will approach unity and this is more pronounced in the hollow fiber than in the Kolff and Kiil dialyzer as shown in figures (9), (10) and (11). These are compared with the countercurrent behavior shown in figure (12). Another parameter is the permeability where it is not the maximum permeability of the membrane but an integral expression of machine efficiency. In this study the permeability for Kiil and Kolff dialyzer as reported in reference [8] compared with the permeability of the hollow dialyzer which has been obtained experimentally and found that in reference [8]. The range of blood flow rate was very high but in the present experiment this was not valid because it induced changes in the hydrodynamic conditions in the apparatus and clinical difficulties. It may cause hemolysis in 
addition to that the diffusion of molecules across the membrane decreases at high flow rates, the interaction between them decreases where the molecules don't have enough time to pass through the membrane. Permeability is directly proportional to the surface area and inversely proportional to the membrane thickness, whereas the value of permeability for area $1.8 \mathrm{~m}^{2}$ is larger than that for $1.6 \mathrm{~m}^{2}$ for the hollow fiber dialyzer. For area $2.1 \mathrm{~m}^{2}$; the permeability value is $756.2 \mathrm{ml} / \mathrm{min}$ for $Q_{b}=350 \mathrm{ml} / \mathrm{min}$ and thickness $50 \mu \mathrm{m}$ for hollow fiber dialyzer while for Kiil dialyzer it is $310 \mathrm{ml} / \mathrm{min}$ for $Q_{b}=400 \mathrm{ml} / \mathrm{min}$ and thickness $0.023 \mathrm{~mm}$, whereas the permeability value is $143 \mathrm{ml} / \mathrm{min}$ for $Q_{b}=250$ $\mathrm{ml} / \mathrm{min}, \mathrm{A}=0.9 \mathrm{~m}^{2}$ and thickness $0.025 \mathrm{~mm}$ for the Kolff dialyzer. Thus, the hollow fiber dialyzer is the largest in permeability as presented in figures (13) and (14).The overall mass transfer resistance for any type of dialyzer is preferable to be low. It is unpredictable and high for coil dialyzer $\left(113 \mathrm{~min} / \mathrm{cm}\right.$ at $\left.Q_{b}=200 \mathrm{ml} / \mathrm{min}\right)$ and lesser for parallel dialyzer $\left(74 \mathrm{~min} / \mathrm{cm}\right.$ at $Q_{b}=200 \mathrm{ml} / \mathrm{min}$ ) while for the hollow fiber dialyzer it is very low (e.g. $16.5 \mathrm{~min} / \mathrm{cm}$ with $1 \mathrm{~m}^{2}$ ) so it is the best as shown in figures (15). The expression of delivered dose using variants of $\mathrm{Kt} / \mathrm{V}$ include $(\mathrm{spKt} / \mathrm{V}$, URR, eKt/V). The spKt/V value should be greater than 1.2. This value increase with increasing area for $(1,1.3,1.7,2.1$ $\left.\mathrm{m}^{2}\right)$ have average $\mathrm{spKt} / \mathrm{V}$ value $(0.796,1.308,1.618,1.636)$ respectively at blood flow rate $300 \mathrm{ml} / \mathrm{min}$. Another popular standard is to keep a minimum URR of $65 \%$. The average URR value at area $\left(1,1.3,1.7,2.1 \mathrm{~m}^{2}\right)$ are $(37.496,68.332$, $69.818,66.87)$ respectively at blood low rate $300 \mathrm{ml} / \mathrm{min}$. However, the relation between the URR and $s p K t / V$ is mediated by the relative weight change during a dialysis session. eKt/V generally is about $0.2 \mathrm{Kt} / \mathrm{V}$ unit lower than $\mathrm{spKt} / \mathrm{V}$. The average eKt/V value at area $\left(1,1.3,1.7,2.1 \mathrm{~m}^{2}\right)$ are $(0.698,1.07,1.402,1.384)$ respectively at blood low rate $300 \mathrm{ml} / \mathrm{min}$. But these values are lower at blood low rate
$200 \mathrm{ml} / \mathrm{min}$. The $\mathrm{Kt} / \mathrm{V}$ values also affected by dialyzer specification especially its area, as the area, blood and dialysate flow rate increase these values $(\mathrm{spKt} / \mathrm{V}$, URR, $\mathrm{eKt} / \mathrm{V}$ ) also increase, as shown in figures (16), (17) and (18), increasing $(\mathrm{spKt} / \mathrm{V}, \mathrm{URR}$, eKt/V) with increase area and blood flow rate for a different dialyzer type.

\section{Conclusions}

1. Kiil, Kolff and hollow fiber dialyzer differ from each other in some features and parameters such as the area of the dialyzer, time of treatment, clearance, flow geometry, cost, multiple use and device age. These parameters will affect the device efficiency. The Kiil device is somewhat less efficient than Kolff device; and the hollow fiber dialyzer is more efficient and effective than these two types and it is widely used nowadays.

2. The clearance depends on the removal rate and dialyzer area, where it increases with increasing area. The area of the dialyzer affects the treatment time; the time decreases with increasing area. The reusability and disposability of the device together with the above factors will affect the adequacy of the hemodialysis.

3. High efficiency dialyzer requires high mass transfer- area coefficient (KoA), high blood, and dialysate flow rates.

4. Increasing membrane surface area leads to increase the efficiency, permeability and dialysis adequacy (spKt/V, eKt/V and URR).

5. The extraction ratio $\mathrm{E}$ approaches unity for increasing values of $N_{T}$ and decreasing values of $Z$. This is more pronounced for the hollow fiber dialyzer than in Kiil and Kolff dialyzers.

6. Time of treatment is very important; and it is high for Kiil and Kolff dialyzers about twice that for the hollow fiber dialyzer. The difference of time between the polysulfone and polyflux is always insignificant.

\section{Appendix}

Table (A-1). Comparison of maximum effective permeability in individual types of artificial kidneys [8].

\begin{tabular}{|c|c|c|c|c|c|c|c|c|}
\hline Type of dialyzer & Numer & Reference & Thickness mm & A $m^{2}$ & $Q_{b} \quad \mathrm{ml} / \mathrm{min}$ & D $m l / \min$ & $\mathbf{P} \mathrm{ml} / \mathrm{min}$ & $\mathbf{P} \frac{m l / \min }{m^{2}}$ \\
\hline \multirow[t]{2}{*}{ Kiil } & 1 & Kiil & 0.011 & 2.0 & 850 & 420 & 580 & 290 \\
\hline & 2 & Freeman & 0.023 & 2.1 & 400 & 215 & 310 & 148 \\
\hline \multirow{8}{*}{ Skeggs- Leonards } & 3 & Jorgensen & 0.011 & 3.8 & 725 & 370 & 520 & 137 \\
\hline & 4 & Jorgensen & 0.011 & 2.5 & 725 & 250 & 325 & 130 \\
\hline & 5 & Smith & 0.010 & 3.0 & 300 & 231 & 440 & 147 \\
\hline & 6 & Smith & 0.020 & 3.0 & 200 & 191 & 310 & 103 \\
\hline & 7 & Smith & 0.010 & 2.0 & 200 & 191 & 310 & 155 \\
\hline & 8 & Smith & 0.020 & 2.0 & 275 & 152 & 212 & 106 \\
\hline & 9 & Maher & 0.020 & 2.0 & 275 & 152 & 212 & 106 \\
\hline & 10 & Soviet & 0.020 & 1.5 & 275 & 148 & 212 & 141 \\
\hline \multirow[t]{2}{*}{ Rotating drum } & 11 & Merrill Wolf & & 2.2 & 500 & 300 & 457 & 212 \\
\hline & 12 & Antoine & & 3.0 & 600 & 287 & 494 & 165 \\
\hline \multirow[t]{2}{*}{ Alwall } & 13 & Alwall & & 1.6 & 473 & 237 & 328 & 206 \\
\hline & 14 & Alwall- Prague & 0.028 & 1.2 & 400 & 80 & 90 & 77 \\
\hline \multirow{4}{*}{ Coil Kidney } & 15 & Elliot & 0.025 & 1.8 & 300 & 174 & 260 & 145 \\
\hline & 16 & Kolff & & 0.9 & 250 & 110 & 143 & 159 \\
\hline & 17 & Kolff & & 0.6 & 100 & 60 & 100 & 159 \\
\hline & 18 & Kolff & & 0.3 & 150 & 38 & 46 & 146 \\
\hline Chronic-A-Coil & 19 & Freeman & & 0.9 & 250 & 108 & 140 & 156 \\
\hline
\end{tabular}


List of symbols

\begin{tabular}{llc}
\hline Symbol & Meaning & Unit \\
\hline$D^{\prime \prime}$ & Diffusivity & $\frac{\mathrm{cm}^{2}}{\mathrm{~s}}$ \\
$D_{B . M . D}^{\prime \prime}$ & Diffusivity in blood, membrane, dialysate & $\frac{\mathrm{cm}^{2}}{\mathrm{~s}}$ \\
$K_{\circ}$ & The overall mass transfer coefficient & $\frac{\mathrm{cm}}{\mathrm{min}}$ \\
& & $\frac{\mathrm{min}}{\mathrm{cm}}$ \\
$R_{\circ}$ & The overall mass transfer resistance & $\mathrm{cm}$ \\
$A$ & Area & $\frac{\mathrm{ml}}{\mathrm{min}}$ \\
$Q_{b} \cdot Q_{d}$ & Blood and dialysate flow rate & $\mathrm{mmol} / \mathrm{l}$ \\
$C_{b} \cdot C_{d}$ & Concentration in blood and dialysate & - \\
$i, \mathrm{o}$ & Inlet and Outlet & $\mathrm{ml}$ \\
$\mathrm{D}$ & Dialysance & $\mathrm{min}$ \\
$N_{T}$ & The number of mass transfer units & - \\
$\mathrm{E}$ & The extraction ratio & - \\
$\mathrm{Z}$ & Ratio of blood on dialysate flow rate & - \\
$C_{t}, C_{o}$ & Session time & $\mathrm{hr}$. \\
$U F$ & The start and end session urea concentration & $\mathrm{mmol} / \mathrm{l}$ \\
$W$ & The weight loss & $\mathrm{Kg}$ \\
$V_{b o d y}$ & The end session body weight & $\mathrm{Kg}$ \\
\hline & Body volume & $\mathrm{l}$ \\
\hline
\end{tabular}

\section{References}

[1] Lai1 M. H., Nieh H. M., Teng T. P., Chen J. J., Huang Y. Y., Lu Y. C., "Development of an Hemodialysis Simulator for Interdisciplinary Learning", IEEE, pp. 2493-2497,2010.

[2] Claudio Ronco, Bernard Canaud, Pedro Aljama,"Solute Removal by Hollow-Fiber Dialyzers", Hemodiafiltration, Vol. 158, pp. 20-33, karger, 2007.

[3] Christopher Kirwan and Andrew Frankel," The Artificial Kidney", Artificial Organs, Springer, 2009.

[4] David O. Cooney, "Artificial Kidney Devices", Biomedical Engineering Principles, Marcel Dekker, 1976.

[5] Vander et al," The Kidneys and Regulation of Water and Inorganic Ions", Human Physiology: The Mechanism of Body Function, 8 editions, McGraw-Hill Companies, 2001.

[6] William Drukker, John A. Sargent and Frank A. Gotch, "History of Hemodialysis, Principles and Biophysics of Dialysis", Replacement of Renal Function by Dialysis: A Text Book of Dialysis, Kluwer Academic Publishers, third edition, 1989.

[7] Narender P. Reddy, "Modeling and Simulation of Biomedical Systems", Standard Handbook of Biomedical Engineering and Design, McGraw-Hill, 2004.

[8] Albert Valek and Rene Tomasek,"comparison of efficacies of various types of artificial kidney", pp. 340-345, 1966.

[9] Thomas A. Depner, "Hemodialysis adequacy: Basic essentials and practical points for the nephrologist in training", Hemodialysis International, 9, pp 241-254, 2005.

[10] John T. Daugirdas and John C. Van Stone, and James T. Boag"Physiologic Principles and Urea Kinetic modeling, Hemodialysis Apparatus", Handbook of Dialysis, 2nd and 3rd edition, Lippincott Williams \& Wilkins Publishers, 2000.

[11] Thomas A. Depner,"Assessing adequacy of hemodialysis: Urea modeling", Kidney International, Vol. 45, pp. 1522-1535, 1994.

[12] Sadiq Jafer Abbass, Zainab Ismail Al-Salihi," The Effect Of Increasing Dialysate Flow Rate In Hemodialysis", College of Engineering Journal (NUCEJ) Vol.10, No.1, pp.72-79, 2007.

[13] Benjamin A. Halpren, Stanton G. Axline, Norman S. Coplon, and Debera M. Brown," Clearance of Gentamicin during Hemodialysis: Comparison of Four Artificial Kidneys", Vol. 133, No. 6, Oxford journals, pp. 627-636, 1976.

[14] Kaye M. and Posen G. A., "Adaptation of a travenol kidney for chronic dialysis using a Kiil dialyzer and a sterile dialysate circuit", Vol.10, American Society for Artificial Internal Organs, 1964

[15] Ahmad Taher Azar,"Increasing Dialysate flow Rate Increases Dialyzer Urea Clearance and Dialysis Efficiency: an in Vivo study", Saudi Journal of Kidney Diseases and transplantation, 20(6):1023-1029, 2009. 